\title{
A Descriptive Correlational Study Examining the Relationship of Emergency Department Contextual Factors and Transfer Interval to an Intermediate Unit
}

Mary K. Tankersley

Cedarville University, Maryt2911@gmail.com

Follow this and additional works at: http://digitalcommons.cedarville.edu/nursing theses

Part of the Nursing Commons

\section{Recommended Citation}

Tankersley, Mary K., "A Descriptive Correlational Study Examining the Relationship of Emergency Department Contextual Factors and Transfer Interval to an Intermediate Unit" (2015). Master of Science in Nursing Theses. 20.

http://digitalcommons.cedarville.edu/nursing_theses/20 



\section{A DESCRIPTIVE CORRELATIONAL STUDY EXAMINING THE RELATIONSHIP OF EMERGENCY DEPARTMENT CONTEXTUAL FACTORS AND TRANSFER INTERVAL TO AN INTERMEDIATE UNIT}

A thesis submitted in partial fulfillment of the requirements for the degree of Master of Science in Nursing

By

MARY KATHERINE TANKERSLEY

B.S.N. Wright State University, 2003

2015

Cedarville University 


\begin{abstract}
The number of emergency department (ED) visits in the US has increased over the past 20 years. In 1993 there were 90 million visits to the ED. In 2003 this number increased by $27 \%$ to 114 million while the population increased by only $12 \%$. This statistic reveals there was more than one ED visit for every three people in the US in 2003 (Institute of Medicine, 2006). Patients who present to the Emergency Department (ED) during overcrowded conditions have an increased length of stay and increased risk of inpatient mortality compared to non-overcrowded conditions (Medicare.gov, N.D.). Overcrowding has been defined as a situation where the need for emergency services is greater than the available resources in the emergency department (Committee on Pediatric Emergency Medicine, 2004; American College of Emergency Physicians, 2005). Overcrowded conditions compromise delivery of quality care, decreases patient satisfaction, and increases risk for patients with serious illnesses or injuries (Medicare.gov, N.D.). It has been a problem reported by $90 \%$ of hospital directors (Parks, Klein, Frankel, Friese \& Shafi, 2008). The purpose of this study was to determine the relationship between factors affecting overcrowding in the ED and departure time of patients in a midWestern urban hospital. This was a descriptive correlational study set in Riverside Methodist Hospital in Columbus, Ohio of 192 eligible patients transferred from the ED to an intermediate unit from January 1, 2015 to January 31, 2015. A retrospective chart review was done to collect the following data: transfer intervals, ED nurse staffing numbers, ED census, and ED acuity levels. Statistical analysis included Pearson r, t-test, ANOVA with post hoc analysis, and multiple regression analysis using the software Statistical Package for the Social Sciences (SPSS). There was a strong positive correlation between the transfer interval and number of acuity level ESI-4 patients ( $\mathrm{p}=.008)$. The transfer interval time was lengthened as the number of
\end{abstract}


acuity level ESI-4 patients increased in the ED. There was no correlation between the transfer interval and ED census or RN staffing. This is an indication there were other factors in the ED which affected transfer interval which were not identified in this study. Transfer interval time of patients being transported to the intermediate unit should be consistently assessed to identify opportunities for improvement. 


\section{Table of Contents}

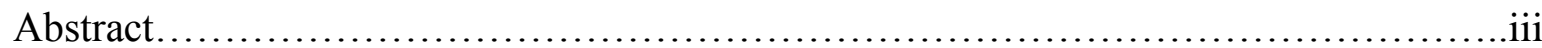

Table of Contents............................................................

List of Figures and Tables....................................................

Acknowledgement........................................................... vii

Chapter 1: Introduction and Literature Review................................ 1

Chapter 2: Theoretical Model................................................. 9

Chapter 3: Methodology..................................................... 11

Chapter 4: Results........................................................ 16

Chapter 5: Discussion...................................................... 19

Appendix A: OhioHealth IRB Approval Letter.....................................23

Appendix B: Cedarville IRB Approval Letter.......................................25

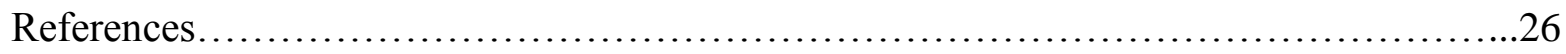




\section{List of Figures and Tables}

Figure 1: ED Timestamps and Intervals.....................................

Figure 2: Input-Throughput-Output Conceptual Model of ED Overcrowding........10

Table 1: Data Analysis..................................................... 18

Table 2: Incidental Findings.............................................. 21 


\section{Acknowledgement}

I would like to thank my committee chair Dr. Amy Voris and committee members Professor Connie Ford and Dr. Sharon Christman for their valuable time spent with me constructing this paper. My parents, Michael and Ann, have always encouraged and supported me to pursue whatever God has called me to do. Heavenly Father, thank you is not enough. 


\section{Chapter One: Introduction and Literature Review}

Emergency Department (ED) overcrowding has been a problem reported by $90 \%$ of hospital directors (Parks, Klein, Frankel, Friese \& Shafi, 2008). The number of ED visits in the US has increased over the past 20 years. In 1993 there were 90 million visits to the ED. In 2003 this number increased by $27 \%$ to 114 million while the population increased by only $12 \%$ (Institute of Medicine, 2006). This statistic reveals there is more than one visit for every 3 people in the U.S. This increase in use of the ED can lead to overcrowding. The Institute of Medicine (2006) has labeled ED overcrowding as a growing “crisis" (p.1) which could impede people's access to emergency care. These conditions decrease the efficiency of operations in the department which causes a ripple effect on other floors of the hospital, ambulances, and the community (IOM, 2006). Current research shows overcrowding decreases health care quality by increasing the chance of creating a medication error, prolonging pain and suffering, and lowering patient satisfaction scores (Jenkins, O'Conner, \& Cone, 2006; Committee on Pediatric Emergency Medicine, 2004; Gordon, Billings, Asplin, \& Rhodes, 2001). Overcrowding in the ED leads to ambulance diversion causing substantial delays in ambulance transport regardless of patients' severity of illness (Schull, Morrison, Vermeulen, \& Redelmeier, 2003). The Joint Commission on Accreditation of Healthcare Organizations (JCAHO) cites overcrowding as the cause of over half of the sentinel events reported which resulted in a patient death or permanent injury due to delay of care in the ED (Parks et al., 2008).

Many organizations have attempted to define overcrowding within an emergency department. The Committee on Pediatric Emergency Medicine defines overcrowding as a phenomenon where emergency room capacity and emergency medical services are completely saturated (2004). This includes rooms and available space, as well as medical equipment and 
qualified staff. According to the American College of Emergency Physicians, overcrowding is a situation where the "need for emergency services outstrips available resources in the emergency department" (CPEM, 2004, p.881). It has further been defined as a condition when the demand for emergent care "exceeds the available supply or there is an inability to move patients to inpatient areas" (Barrett, Ford \& Ward-Smith, 2012, p.82). Each of these definitions includes complete usage of its resources and demand for more. In summary, overcrowding is a condition where demand exceeds capacity.

Literature reveals two terms used interchangeably to convey this phenomenon in the ED: "overcrowding" and "crowding" (Moskop, Sklar, Geiderman, Schears, \& Bookman, 2008). JACHO uses the term "overcrowding" to discuss current issues in patient flow in the ED (2012). The American College of Emergency Physicians defines "overcrowding" as "institutional resources available are insufficient to meet the basic service needs of emergency patients" (ACEP, 2005, p.7). In order to maintain consistency, this paper will only use the term "overcrowding".

Length of stay has been documented as a manifestation of overcrowding within the ED (Singer, Thode, Viccellio, \& Pines, 2011). Patients who have an increased length of stay take up vital space in the ED causing overcrowded conditions. Several studies have given notice to a strong relationship between increased length of stay in the ED and hospital mortality (Singer et al., 2011; Moskop, et.al, 2009; Richardson, 2006). One study found patients who had a six hour or greater delay in ICU transfer had increased hospital stay and mortality rate (Chalfin, Treciak, Likourezos, Baumann, \& Dellinger, 2007). Another study found ED overcrowding increased length of stay in all high acuity patients and attributed this largely to output factors, such as, factors associated with transferring patients out of the department (McCarthy, Zeger, Ding, 
Levsin, Desmond, Lee, \& Aronsky, 2009). McCarthy et.al also found length of stay for the Emergency Severity Index level one patients was not affected by high volume. This could be due to staffing and resources prioritized to the sickest patient in the department allowing for the longer length of stay in level two and three patients. In contrast to the study done by Hwang, et.al cited earlier, McCarthy et.al noted treatment time in the ED was not affected by high volume conditions, although wait time and boarding time increased significantly (McCarthy, et.al, 2009). A study examining the relationship between length of stay and left without being seen rates determined there was no relationship between length of stay and total patient census, whereas there was a strong correlation between length of stay and number of high acuity patients (Graham, Aitken, \& Shirm, 2011). Delay in transfer increases length of stay, which in turn delays care of patients in the waiting room and arriving by ambulance. Chalfin et al., (2007) gives further light to the situation of delay in transfer of patients from ED to ICU stating "since the critically ill may benefit from the highly specialized and skilled environment of the ICU or in any clinical setting where the appropriate care is provided, it stands to reason that delayed transfer to ICU, or the delayed provision of critical care services regardless of patient location, may be potentially deleterious" (p.1480).

Overcrowded conditions are manifested by demand for resources as seen by three factors in the ED. Staffing is a key factor in maintaining efficiency of operations in the ED. The Committee on Pediatric Emergency Medicine (2004) stated "experienced ED nurses are truly the backbone of emergency care” (p.883). O’Brien-Pallas, Murphy, Shamian, Li, \& Hayes (2010) postulated "stable nurse staffing and adequate managerial support are essential to promote job satisfaction and high-quality patient care" (p.1073). Poor staffing is correlated with an increase 
in hospital-acquired urinary tract infections, pneumonia, and poor patient satisfaction (Agency for Healthcare Research and Quality, 2008).

According to the Institute of Medicine (2006), "when patient volume exceeds inpatient capacity, the excess volume tends to back-up in the ED” (p.30). The ED census accounts for the number of patients in the waiting room and in the total number of patients in the ED. These numbers increase in times of overcrowding and are directly affected by decreased numbers of inpatient beds, high inpatient census, and influx of ED presentations (Flabouris, Jeyadoss, Field, \& Soulsby, 2012). A high census in the ED has been shown to prolong the length of time it takes for a patient to receive analgesic medication (Hwang, Richardson, Livote, Harris, Spencer, \& Morrison, 2008). Hwang, et.al, reported a direct correlation between ED census and increased time to a pain assessment, time to orders for analgesic medications, and time to administration of the medication. There was an average delay of 43 minutes for time to administration of analgesic medications during periods of high census (Hwang, et.al, 2008).

Acuity can also change the pace within the ED. ED staff is frequently allocated to care for high acuity level patients decreasing the amount of time spent caring for other patients (Singer, Thode, Viccellio, \& Pines, 2011). In 1999, ED directors reported increasing patient acuity was the top contributing factor in overcrowding (Derlet, Richards, \& Kravitz, 2001). The U.S. faces an increase in population and life expectancy along with an increase number of patients having complex comorbidities (Derlet, et.al, 2001). A large amount of resources are restricted to these patients who require an immense amount of care. As inpatient ICU and intermediate units are filled, this backs up the other high acuity patients in the ED, forcing the ED to operate like a make-shift ICU (Derlet, et.al, 2001). Limited resources are then available for the continued flow of critical patients into the ED creating a dangerous environment (Derlet, 
et.al, 2001). For many lower-acuity patients, going to the ED for primary care is a matter of convenience. Indigent patients often view the ED as equitable to outpatient primary care (Grumbach, Keane, \& Bindman, 1993). It is open at all hours of the day and will accept anyone regardless of ability to pay (Cunningham, 2011). This is partly due to the Emergency Medical Treatment \& Labor Act (EMTALA). EMTALA was passed in 1996 and guarantees EDs must provide stabilizing care and hospitalization when necessary (Gordon, et al., 2001). This resulted in a shift of funds within the hospital organization to reimburse the costs of these patients which further straining the availability of resources (Gordon, et al., 2001, p. 1027). Acuity could be measured using a four or five tier triage system (Grumbach, et.al, 1993). For this study, the five tier triage system Emergency Severity Index (ESI) will be used, where level five is the lowest acuity, or least sick, and level one is the highest acuity, or sickest.

In a recent article written by Welch, Asplin, Stone-Griffith, Davidson, Augustine, \& Schuur (2011) attempted to develop a "standard set of definitions about the measurement of ED operational performance" (p.33). Figure 1 below was formulated to display a typical ED visit starting with patient arrival and ending with patient departure. The definitions are supported by the Emergency Nurse's Association's (ENA) (2011) provided in the 2011 Consensus Statement concerning "Definitions for Consistent Emergency Department Metrics" (p.1). The ENA (2011) defines length of stay as "ED arrival time to ED departure time" (p.2). The ENA (2011) defines departure time as the time the patient has physically left the department. It further states it is "the time most closely represented by being out of the department and no longer the ED's responsibility" (p.2). In Figure 1, intervals between different timestamps are measured. There is a time interval measuring the decision to admit a patient to the ED departure time. There is also an interval measuring the time a bed is requested to when the bed is available and ready to 
receive the patient. There is no identified interval which considers the time a patient has a bed available to when the patient physically leaves the ED to go to the bed assignment. There is a gap in the literature examining this interval and its relation to staffing in the ED, patient acuity in the ED, and ED census. From the time a bed is available, it becomes the primary nurse's responsibility to call report to the floor accepting the patient and to document the time the patient departs from the ED. In cases of patients with high acuities, such as critical care or intermediate care, the nurse also has the task of personally transporting the patient to the bed assignment to ensure a safe transfer to experienced personnel on the floor. The main variable in this interval is the primary nurse as it is their responsibility to acknowledge when the bed is available, call report to the receiving nurse, and transport the patient to the bed assignment.

Figure 1.

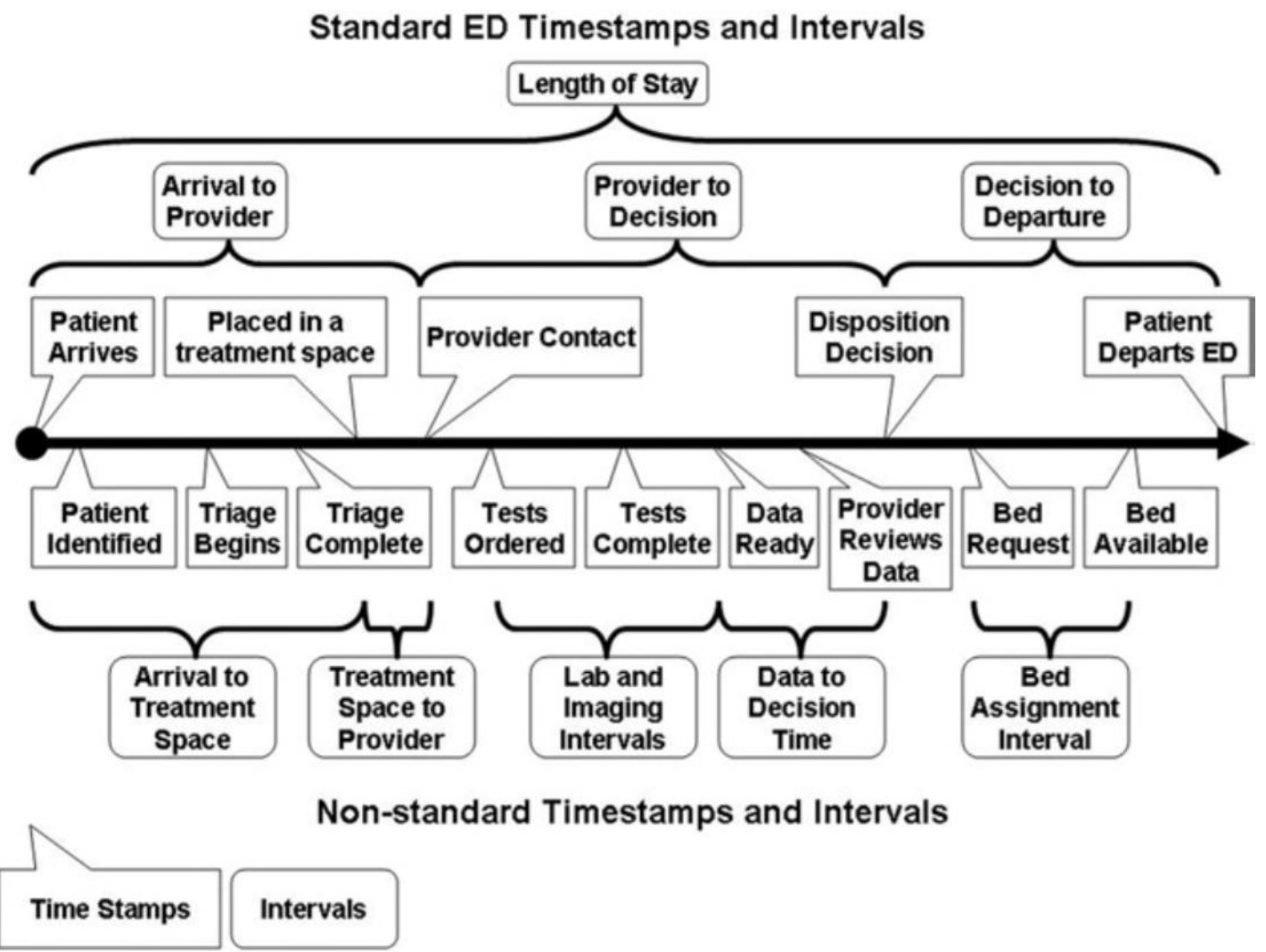

ED Timestamps and Intervals (Welch, et.al, 2011, p.35) 
The Centers for Medicare and Medicaid currently publicizes data from thousands of Medicare-certified hospitals which focuses on quality of care provided by these hospitals. This information is to facilitate patients finding hospitals which best suit their needs. It also encourages hospitals to improve their Centers for Medicare and Medicaid scores. One criterion for quality care in the ED is "Average (median) time patients spent in the emergency department, after the doctor has decided to admit them as an inpatient before leaving the emergency department for their inpatient room”. JCAHO (2012) has also implemented a new policy regarding length of stay and "boarded" patients in the ED. According to JCAHO (2012) boarding is "the practice of holding patients in the ED or another temporary location after the decision to admit or transfer has been made" (p.2). It sets a new standard goal for boarding time not to exceed four hours. JCAHO advocates for these metrics to be publically reported as well. This may eventually put the accreditation of hospitals at risk if their boarding times are excessive which could indicate a decrease in patient safety and quality of care.

Length of stay could be an indicator of poor staffing within the department. Another study completed in 2006 found inappropriate staffing accounted for $15 \%$ of the delays in transfer from ED to ICU (Gillman, Leslie, Fawcett, Bell, \& McGibbon, 2006). Nurse staffing is only one element of ED length of stay but an important one. Without appropriate nursing staff, nurses are not able to care for patients in a timely manner. Caring for the critically ill within the ED for long periods of time is not what most ED's are designed or staffed for (Chalfin et al., 2007). It is unclear how decreased staffing levels associate with length of stay, specifically the time when nurses are able to transfer patients to critical care or intermediate beds. 
While many studies have been done concerning factors effecting length of stay in the ED, there are a limited number of studies providing insight as to how staffing of nurses impact length of stay and ED departure time. McCarthy et al, (2009) studied boarding time, or the time from physician decision to admit to the departure time out of ED. This study did not include the time a bed was ready to the time of departure from ED. Singer et al, also focused on time from the decision to admit the patient to transfer to floor (Singer et al., 2011). A study by Gillman, et.al, looked at the number of adverse events which took place while transferring a critically ill patient from the ED to the ICU. It noted $30 \%$ of the delays were due to lack of ICU bed, while $15 \%$ were due to lack of ICU staffing (Gillman et al., 2006). It did not show any correlation to staffing in the ED. Considering the importance placed on length of stay by the Institute of Medicine and new regulations put in place by JCAHO, this is an important metric which impacts all ED's nationwide. ED administration should be researching factors that affect length of stay in order to provide quality care.

The purpose of this study was to explore relationships between length of stay and ED contextual factors (staffing, census and acuity) in relation to the time it takes for patient transfer to an intermediate hospital bed once a bed has been determined to be ready. 


\section{Chapter Two: Theoretical Model}

Asplin, Magid, Rhodes, Solberg, Lurie, \& Camargo (2003) developed the InputThroughput-Output Conceptual Model of ED Overcrowding. It is a practical framework about ED crowding and contributing factors in order to assist other researchers, policymakers and managers. This model contains three interdependent components to ED increased length of stay: input, throughput, and output. The input element focuses on any situation which utilizes ED services. Factors influencing input could include the demand for healthcare services, any predisposing factors affecting the individual's likelihood of seeking care, and enabling factors affecting an individual's ability to receive care (Asplin, et.al, 2003). Factors effecting throughput include internal operations of the ED such as the triage process and testing and treatment up to the disposition decision, which is admission, discharge or transfer from the ED. Factors effecting output includes bed availability and lack of access to follow-up care. If there is a lack of available unit bed or staffing, the patient is considered to be boarded in the ED and re-enters the throughput component. (Asplin et al., 2003)

Figure 2 represents the Input-Throughput-Output conceptual model of ED overcrowding (Asplin et al., 2003). The variables in this study correlate with this theoretical model. ED staffing, census, and acuity are all contextual factors which theoretically affect throughput times. When ED staffing numbers are low, there may be less staff to complete nursing tasks which in turn causes an increase in length of stay. As census in the ED rises, less ED beds are available for patient evaluation and treatment. When there are patients in the ED with high acuities, lower acuity patients suffer delays in care due to the sickest patients requiring more resources. Patient output is when the patient departs from the ED and transfers to the floor. Transfer interval is the time from when a patient has a ready bed and admitting orders to when they depart from the ED. 
This variable affects both throughput and output. After application of this theory, this researcher presented three hypotheses:

Hypothesis 1: There will be a significant positive correlation between ED census and transfer interval.

Hypothesis 2: There will be a significant negative correlation between ED staffing and transfer interval.

Hypothesis 3: There will be a significant positive correlation between ED acuity level and transfer interval.

Figure 2

The Input-Throughput-Output Model of ED Overcrowding (Asplin, et.al, 2003, p.176)

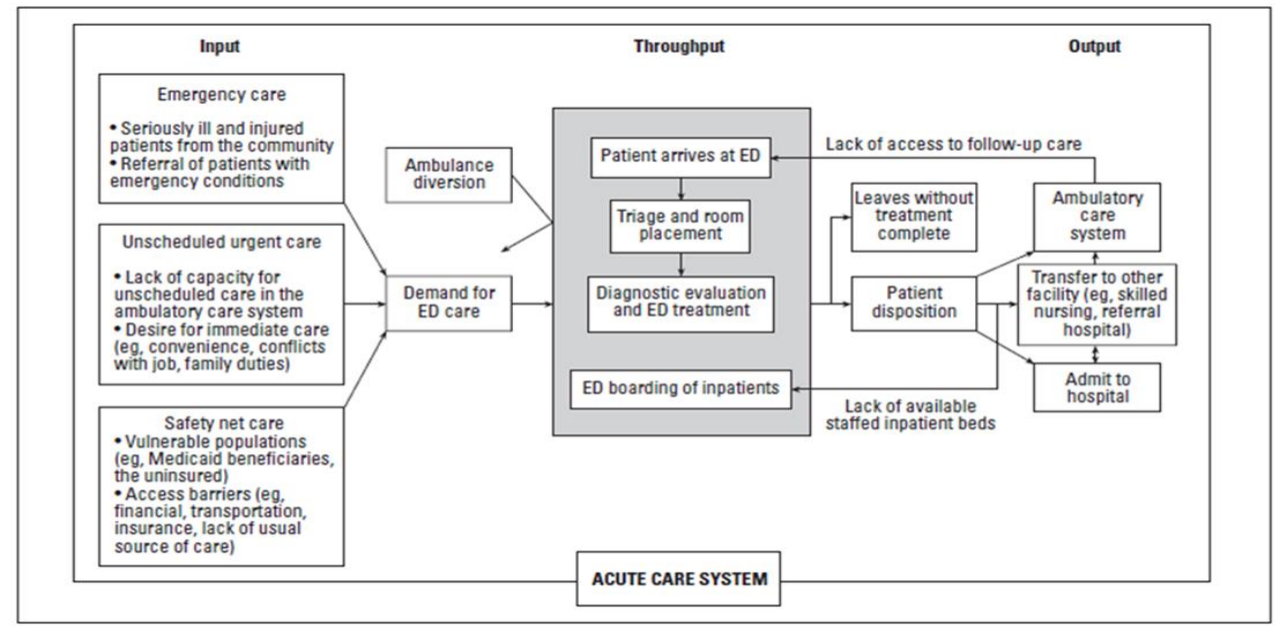




\section{Chapter Three: Methodology}

This was a descriptive correlational study designed to examine the relationship between transfer interval time for patients admitted to intermediate hospital beds and ED staffing, census and acuity. This study was a retrospective chart review of patients admitted from the ED to intermediate hospital beds at Riverside Methodist Hospital (RMH) between the dates of January 1, 2015 to January 31,2015 . The aim of this study was to examine the transfer interval time in relation to ED contextual factors. The specific ED contextual factors were as follows: ED nurse staffing, total ED census, and acuity levels using the Emergency Severity Index triage system (ESI level 1, ESI level 2, ESI level 3, ESI level 4, and ESI level 5). This researcher aimed to determine if there was a correlation between transfer interval time and ED nurse staffing, transfer interval time and total ED census, transfer interval time and total number of ESI level 1 in the ED, transfer interval time and total number of ESI level 2 in the ED, transfer interval time and total number of ESI level 3 in the ED, transfer interval time and total number of ESI level 4 in the ED, and transfer interval time and total number of ESI level 5 in the ED. Statistical analysis included Pearson r, t-test, and multiple regression analysis using the software Statistical Package for the Social Sciences (SPSS).

The staffing data was gathered from clinical nurse manager (CNM) safety checklists completed by the ED charge nurses at each shift change. These checklists have been utilized to monitor various safety factors in the ED, such as staffing, total number of admitted patients, and total number of IV pumps in the department for several years and are currently archived in the ED administrative office. The transfer interval time was obtained from the individual electronic medical records specific to the ED (EMSTAT). EMSTAT provided a total ED census snapshot, 
including the number of patients at each acuity level to the exact minute a patient's bed was ready and admitting orders were completed.

The population included patients seen in the emergency department and subsequently admitted to the step-down ICU (STICU) unit from January 1, 2015 to January 31, 2015. The rationale for studying STICU patients is nurses are required to transfer patients to this unit and therefore have control over the transfer interval. Riverside Methodist Hospital in Columbus, Ohio is a 765-bed certified level 2 trauma facility with 44,000-45,000 admissions and 88,000 visits to the ED annually (U.S. News \& World Report).

\section{Exclusion Criteria}

Exclusion criteria include any ED patient admitted to any unit other than STICU or transferred to any other part of the hospital (e.g. surgery, MRI). The transfer interval on these patients would be considerably longer than patients transferred directly to the bed assignment which would skew the study results.

Study Variables

Transfer interval: Dependent variable. Transfer interval was determined by accessing the EMSTAT of each patient transferred to the STICU. This researcher recorded the time an inpatient bed became available concurrent with admitting orders completed, and the time the patient was discharged from the EMSTAT. The time when both an inpatient bed and admitting orders have been completed is documented to the minute in EMSTAT. This time was subtracted from the EMSTAT discharge time, and the difference was recorded in minutes.

Nurse Staffing: Independent variable. Nurse staffing was defined as the number of registered nurses in the ED at the time of bed availability and orders completed for each patient. Nurse staffing was recorded every shift change $(0700,1100,1500,1900,2300,0300)$ on the 
CNM Safety Checklist. The nurse staffing number recorded at the time prior to the bed availability and orders completed time was recorded. For example, if that time occurred at 0850 , then the 0700 nurse staffing number was recorded.

Census: Independent variable. Census was defined as the total number of patients in the ED at the time of concurrent bed availability and orders completed for each patient. This variable is recorded to the minute in EMSTAT.

Acuity: Independent variable. Emergency Severity Index (ESI level 5, ESI level 4, ESI level 3, ESI level 2, \& ESI level 1) is the 5-tier triage system used in the RMH ED to determine the acuity of each patient. For this study, acuity was defined as the number of patients at each acuity level at the time of concurrent inpatient bed availability and orders completed for each patient. For example, the variable Acuity5 was the number of patients in the ED at that acuity level; Acuity 3 was the number patients in the ED at that acuity level; and Acuity1 was the number of patients in the ED at that acuity level. This data can be found in and recorded from EMSTAT.

\section{IRB Approval Process}

This researcher first submitted this study for OhioHealth IRB approval in January 2015. After minor revisions to the study were made, approval was obtained on March 31, 2015 (Appendix A). Cedarville IRB approval was obtained on May 21, 2015 (Appendix B).

\section{Data Collection}

Every day the ED nurse manager generates a list of all the patients that were transferred to the STICU. After being given permission by the ED nurse manager, this researcher used this to generate the list of subjects for this study. Once an eligible patient was identified, their electronic medical record from their ED stay (EMSTAT) was accessed to determine transfer 
time, acuity level and census. For these same patients, this researcher accessed the CNM Safety Checklist to record nurse staffing. In cases where missing or unclear data exists in the CNM safety checklist, patients who had a ready bed during that particular shift change were excluded. The nurse manager gave this researcher permission to review the safety checklists.

A multiple regression analysis was conducted using the SPSS software. This analysis

allowed this researcher to test relationships between more than one independent variable and the dependent variable simultaneously. In addition, the output generated in SPSS from a multiple regression included a Pearson R between each variable. This researcher tested the dependent variable (transfer interval) and independent variables (nurse staffing, census, and acuity levels). Ethical Considerations

There was no risk for the subjects involved in this study because no patient identifiers were recorded, and none of the data was HIPAA protected (staffing, census, acuity, transfer time). All data was recorded in a SPSS file located on this researcher's laptop which was password protected and never out of the researcher's possession. Limitations 


\section{Chapter Four: Results}

\section{Data Analysis}

The OhioHealth Institutional review board approval was obtained for the conduct of this study on March 31, 2015 (Appendix A). The Cedarville University Institutional review board was obtained for the conduct of this study on May 21, 2015 (Appendix B). Eligible subjects of this study were patients from the emergency department directly admitted to STICU at Riverside Methodist Hospital between January 1, 2015 and January 31, 2015.

The main variables in this study include the transfer interval time, ED nurse staffing, ED census, and ED acuity. After each eligible subject was identified, the ED chart was accessed from the electronic medical record database, EMSTAT. The transfer interval was calculated as the time a patient had a ready inpatient bed concurrent with completed admitting orders to when they was discharged from EMSTAT. This time is calculated in minutes. A snapshot of the ED was obtained at the minute each patient had a ready inpatient bed concurrent with completed admitting orders. This snapshot provided the total ED census and number of patients at each acuity level. The number of nurses in the ED was recorded from the CNM safety checklist. The nurse staffing number recorded at the shift prior to the time of ready bed and admitting orders was recorded.

The data was recorded using PSPP software, converted and analyzed using SPSS software in order to use a multiple regression analysis (Table 1). Descriptive statistics including mean and standard deviation were used to present clinical characteristics. Pearson r, t-test, ANOVA with post hoc analysis, and multiple regression analysis were used to explore correlations and causality between the variables. The total number $(\mathrm{N})$ of eligible subjects for 
this study was $\mathrm{N}=192$. Among these 192 subjects, the mean transfer interval time was 77.38 minutes (8.00-245.00). RN staffing was recorded every four hours at shift changes.

Pearson correlation was used to explore correlations between ED census and transfer interval. The mean ED census was 61.11 (range = 15-114). There was a weak relationship between ED census and transfer interval $(r=.034)$.

Pearson correlation was used to explore correlations between ED staffing and transfer interval. Mean number of RN staff at the time of ready inpatient bed and admitting orders was 23.48 (range $=12-28$ ). There was a weak relationship between ED nurse staffing and transfer interval $(\mathrm{r}=.022)$.

A multiple regression analysis was used to identify strength of correlations between acuity levels and transfer interval time. The mean number of ED acuity level ESI-1 was 1.53 $($ range $=0-5)$, ESI-2 was $18.68($ range $=3-46)$, ESI-3 was $34.62($ range $=6-62)$, ESI-4 was 5.91 (range $=0-14)$, and ESI-5 was .30 (range $=0-3)$. There was a strong positive correlation between the number of ED acuity level ESI-4 in the department and transfer interval time $(\mathrm{p}=.008)$. One way ANOVA with post-hoc analysis also showed a significant interaction between transfer interval and number of ED acuity level ESI-4 in the department $(\mathrm{p}=.015)$. There were no other correlations between the remaining acuity levels and transfer interval time. 
Table 1

Data Analysis

\begin{tabular}{lll}
\hline Variable & Mean $( \pm$ Standard Deviation $)$ & Pearson R
\end{tabular}

Transfer Interval

$77.38( \pm 37.07)$

(minutes)

Acuity

ESI-1

ESI-2

ESI-3

ESI-4

ESI-5

$1.53( \pm 1.31)$

$18.68( \pm 7.17)$

$34.62( \pm 10.93)$

$5.91( \pm 3.27)$

$0.30 \quad( \pm 0.57)$

$\mathrm{r}=.050(\mathrm{p}=.244)$

$\mathrm{r}=-.017(\mathrm{p}=.407)$

$\mathrm{r}=.013(\mathrm{p}=.431)$

$\mathrm{r}=.175(\mathrm{p}=.008)$

$\mathrm{r}=-.018(\mathrm{p}=.401)$

Census

$61.11( \pm 18.82)$

$r=.034$

RN Staffing

$23.48( \pm 4.51)$

$r=.022$ 


\section{Chapter Five: Discussion}

\section{Discussion}

There was a strong positive correlation between the transfer interval and number of acuity level ESI-4 patients. This could be a consequence of RN staffing providing care to level ESI-4 patients prior to transferring the intermediate patients to the bed assignment. The longer it takes to transfer patients out of the ED, the longer lower acuities wait for treatment. Patients with lower acuities, such as level ESI-4 and ESI-5, typically are the last patients to receive a treatment room in the ED. Other unidentified factors could have caused delays in transfer interval causing accumulation of level ESI-4 patients within the ED. There was no correlation between the number of highest acuity patients (ESI-1) in the department and transfer interval.

\section{Limitations}

There were several limitations to this study. First, some inaccuracy was found when transfer interval was measured. The time a patient was discharged from EMSTAT may not have been the exact time the patient physically departed the ED. For example, the nurse may not have discharged the patient out of EMSTAT until after they had transferred the patient to STICU and return to the ED. However, because this is the same measurement Medicare and Medicaid used to measure ED length of stay, this researcher used this same method to measure transfer interval.

A second limitation was this study only explored STICU transfers. This limited the study's generalizability for other units. It would be beneficial to examine transfer intervals for all hospital units. STICU transfers were exclusively examined in this study because it was RMH policy a nurse physically transferred the patient to that particular unit. This removed the extraneous variable of waiting for patient escort. 
A limitation found while conducting the study was the discovery of several patients admitted to the ICU had a level ESI-2 acuity. It may be beneficial for another study to examine the type of hospital admission (ICU, intermediate, telemetry, medical/surgical) in relation to transfer interval in place of the acuity. This may give a more accurate representation of resources being used in the department. Another limitation was the length of the study allowed only 192 eligible subjects for this study. A study on a larger scale could provide stronger relationships.

\section{Incidental Findings}

This study found significant differences between day shift and night shift (Table 2).

During the study, it was discovered there were significant differences between day $(0700-1859)$ and night (1900 - 0659) shift. Independent T-tests were used to determine these significant differences. There was a statistically significant difference in the transfer interval time between day shift and night shift $(\mathrm{p}=.000)$. The transfer interval time was on average 19 minutes longer for day shift than night shift even though the average number of nurses per shift was similar. The census was significantly higher on day shift than night shift with a significant increase in acuity level ESI-3 patients. It is possible these patients cause enough strain in the department to lengthen transfer interval time. According to the Emergency Severity Index Implementation Handbook, patients are designated acuity level ESI-3 if they need two or more resources in the department, such as labs, ECG, radiological imaging, and intravenous medication (AHRQ, 2012). When the number of stable patients in the department requiring multiple resources increases, this study suggests transfer interval time increases for patients travelling to an intermediate floor. 
Table 2

Incidental Findings

\begin{tabular}{lcc}
\hline Variable & Mean \pm Standard Deviation & T test \\
& & \\
\hline Census & $61.11( \pm 18.82)$ & $\mathrm{t}=2.698(\mathrm{p}=.008)$ \\
$0700-1859$ & $65.07( \pm 19.09)$ & \\
$1900-0659$ & $57.83( \pm 18.02)$ & \\
RN Staffing & $23.48( \pm 4.51)$ & \\
$0700-1859$ & $24.09( \pm 3.72)$ & $\mathrm{t}=3.278(\mathrm{p}=.001)$ \\
$1900-0659$ & $22.97( \pm 5.04)$ & \\
Acuity & & \\
ESI-3 & $34.62( \pm 10.93)$ & $\mathrm{t}=3.683(\mathrm{p}=.000)$ \\
$0700-1859$ & $37.39( \pm 11.49)$ & \\
$1900-0659$ & $32.32( \pm 9.93)$ & \\
Transfer Interval (minutes) & $77.38( \pm 37.07)$ & \\
$0700-1859$ & $67.86( \pm 40.41)$ & \\
$1900-0659$ & $68.69( \pm 31.72)$ & \\
\hline
\end{tabular}

\section{Future Research}

This study shed some light on contextual factors in the ED effecting transfer interval time. Medicare and Medicaid consider length of stay a hospital quality indicator. It is important for emergency departments to examine these factors to improve quality and patient safety. Higher numbers of ESI level 3 patients in the department negatively affect transfer times. It would be beneficial for nurses to develop strategies decrease the length of stay for these patients. One study examined the effects of implementing a mid-track area in their ED treating only ESI level 3 patients in order to decrease overall length of stay. While it proved to decrease length of stay for this specific cohort, it increased the length of stay for higher acuity patients (Soremekun, Shofer, Grasso, Mills, Moore, \& Datner, 2014). Further research could help determine if specific resources in the department are affecting timeliness in the ED. Even a small increase in support 
staff may help decrease length of stay for these patients and have a positive effect on overall quality care. Considering nurse staffing between shifts was similar even though census was higher on day shift, it is reasonable that an increase in dayshift nurse staffing may improve timing in the ED.

\section{Conclusion}

Length of stay is a reliable indicator of overcrowding in the ED. Prolonged length of stay has been associated with negative patient outcomes. While research has studied length of stay in an $\mathrm{ED}$, no research has been done to examine the time interval of when a patient is assigned a bed to when they depart the ED (transfer interval). The purpose of this study was to determine the relationship between the transfer interval and ED staffing, census and acuity. This study found the transfer interval time was lengthened as the number of acuity level ESI-4 patients increased in the ED. There were no other significant correlations between transfer interval and the other acuity levels, ED census, or ED staffing. This indicates other factors in the ED affected transfer interval not included in this study. Transfer interval time of patients being transported to the intermediate unit should be consistently assessed to identify opportunities for improvement. 


\title{
Appendix A: OhioHealth IRB Approval Letter
}

\author{
綁翡OhioHealth
}

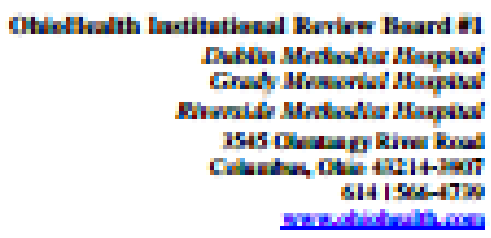

\section{Institutional Review Board Expedited Approval}

March \$1, 2015

Mary Tankersley. RN

1416 Haines Awe

Columbus, $\mathrm{OH} 43212$

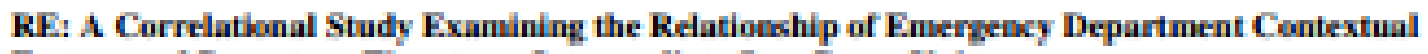
Factors and Departure Time to an Intermediate Step-Down Dbit.

IRB t: OH1-14-101577

Dear Ms. Tunkersley:

Your above-referened potool was appoved under the expedited review proses and will be reputed at

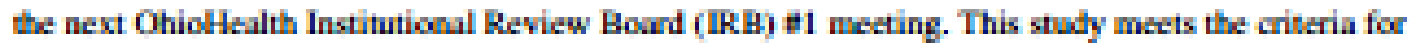
expeditad review under researh casegory 45 CPR 46.110 (b) (1).

Included in the appoval are the tollowing doumenis:

Prococol, Version 4.0 (dased 32015)

CNM Safery Checklis, Versan 2.0

HIFAA fsignod and dahd iRins]

The IRB appronal tor this stody wil epire on 0thandit. Hease submit your Continuing Beview

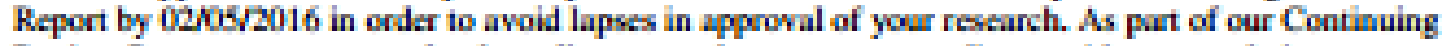
Rariew Process, we may randomly audit your staly to ensure compliane whh our regulatons.

If during the course of the study, there are uy changs ar amenimente, or you decide to beminite the study, plewe noify the IFB Gitice.

The OhaHealh Institutional Review Board is orgunized and operass accoding to the Good Clinical Practices, 21 CRF Pars 46,20 \& 56 and applientle laws and regulations.

As Prindpal Iovesigutor of this protocol, it is your rexpocalbility to keep the all necesary docunestatios pertulaing to the study.

Thank you for your partipution in our IRB review prowes. If you hme any quedions, plese contset the Otice of Regulary Compliance a $(614) 560-4739$.

Sincerty. 
Signature applied by Mary Pat Borgess on 04/31R015 01:4401 PM EDT

Mary Pat Borges, MD

Chair, OhioHealth IRB ti 


\section{Appendix B: Cedarville IRB Approval Letter}

Institutional, Review Board <irb@cedarville.edu>

To: Mary K Tankersley <Maryt2911@gmail.com>

Hi Mary,

Your study has been approved to proceed as specified. Thanks!

Jessic ah Zehring

On Sat, May 2, 2015 at 8:41 PM, Mary K Tankersley<Maryt2911@gmail.com> wrote:

Your Name Mary K Tankersley

Your Email Address Maryt2911@gmail.com

subFolderName 9ad36d4f-78a9-48cc-8637-d1e0ba24e86c 


\section{References}

Agency for Healthcare Research and Quality (2008). Patient Safety and Quality: An EvidenceBased Handbookfor Nurses. U.S. Department of Health and Human Services: Rockville, MD.

American College of Emergency Physicians. (2005). Report from a roundtable discussion: meeting the challenge of emergency department overcrowding/boarding. Washington, DC:ACEP.

Asplin, B.R., Magid, D.J., Rhodes, K.V., Solberg, L.I., Lurie, N., \& Camargo, C.A. (2003). A conceptual model of emergency department crowding. Annals of Emergency Medicine (42)2: 173-180.

Barrett, L., Ford, S., Ward-Smith, P. (2012). A bed management strategy for overcrowding in the emergency department. Nursing Economics, 30(2), 82-116.

Chalfin, D.B., Treciak, S., Likourezos, A., Baumann, B.M., \& Dellinger, R.P. (2007). Impact of delayed transfer of critically ill patients from the emergency department to the intensive care unit. Critical Care Medicine (35)6: 1477-1483.

Committee on Pediatric Emergency Medicine. (2004). Overcrowding crisis in our nation's emergency departments: is our safety net unraveling?. American Academy of Pediatrics, $114(3), 878-888$. 
Cunningham, P. (2011, May). Nonurgent use of hospital emergency departments. Diverting non-urgent emergency room use: can it provide better care and lower costs?. Statement made before the U.S.Senate, Washington, DC.

Derlet, R.W., Richards, J.R., \& Kravitz, R.L. (2001). Frequent overcrowding in u.s. emergency departments. Academic Emergency Medicine 8(2): 151-155.

Emergency nurses association, ED metrics stakeholders meeting, consensus meeting report. (unpublished), presented at: ED metrics stakeholders meeting, July 26, 2010: Washington, DC.

Flabouris, A., Jeyadoss, J., Field, F., \& Soulsby, T. (2012) Association between emergency department length of stay and outcome of patients admitted either to a ward, intensive care of high dependency unit. Emergency Medicine Australasia (25):46-54. Doi: 10.1111/17426723.12021

Gillman, L., Leslie, G., Fawcett, K., Bell, R., \& Mcgibbon, V. (2006). Adverse events experienced while transferring the critically ill patient from the emergency department to the intensive care unit. Emergency Medicine Journal (23):858-861. Doi:

10.1136/emj.2006.037697 
Gordon, J.A., Billings, J., Asplin, B.R., Rhodes, K.V. (2001). Safety net research in emergency medicine: proceedings of the academic emergency medicine consensus conference on "the unraveling safety net”. Academic Emergency Medicine, 8, 1024-1029.

Graham, J., Aitken, M.E., \& Shirm, S. (2011). Correlation of measures of patient acuity with measures of crowding in a pediatric emergency department. Pediatric Emergency Care (22)8: 706-709.

Grumbach, K., Keane, D., Bindman, A. (1993). Primary care and public emergency department overcrowding. American Journal of Public Health, 83, 372-378.

Hwang, U., Richardson, L., Livote, E., Harris, B., Spencer, N., \& Morrison, S. (2008). Emergency department crowding and decreased quality of pain care. Academy Emergency Medicine 15:1248-1255. Doi:10.1111/j.1553-2712.2008.00267.x

Institute of Medicine. (2006). Future of emergency care services: hospital-based emergency care. Washington D.C: The National Academic Press. http://www.annemergmed.com/webfiles/images/journals/ymem/EDfullreport.pdf

Jenkins, J.L., O’Connor, R.E., \& Cone, D.C. (2006). Differentiating large-scale surge versus daily surge. Academic Emergency Medicine, 13, 1169-1172. Doi:101197/j.aem.2006.07.022 
Joint Commission (December 19, 2012). R3 report I requirement, rationale, reference; patient flow through the emergency department. http://www.jointcommission.org/r3 report_issue4/ (accessed on April 21, 2013).

McCarthy, M. L., Zeger, S.L., Ding, R., Levin, S.R., Desmond, J.S., Lee, J., \& Aronsky, D. (2009). Crowding delays treatment and lengthens emergency department length of stay, even among high-acuity patients. Annals of Emergency Medicine (54)4:492-503.

Medicare.gov. Timely and effective care (no publishing date) http://medicare.gov/HospitalCompare/about/HOSInfo/timely-effective-care.aspx (accessed on April 21, 2013).

Moskop, J.C., Sklar, D.P., Geiderman, J.M., Schears, R.M., \& Bookman, K.J. (2009). Emergency department crowding, part 1 - concept, causes, and moral consequences. Annals of Emergency Medicine (53)5: 605-611.

O’Brien-Pallas, L., Murphy, G.T., Shamian, J., Li, X., \& Hayes, L.J. (2010) Impact and determinants of nurse turnover: a pan-Canadian study. Journal of Nursing Management (18): 1073-1086.

Parks, J.K., Klein, J., Frankel, H.L., Friese, R., Shafi, S. (2008). Dissecting delays in trauma care using corporate lean six sigma methodology. The Journal of Trauma Injury, Infection, and Critical Care, 65, 1098-1105. Doi:10.1097/TA.0b013e318188e8ad 
Richardson, D.B. (2006). Increase in patient mortality at 10 days associated with emergency department overcrowding. Medical Journal of Australia (184)5:213-216.

Schull, M.J., Morrison, L.J., Vermeulen, M., \& Redelmeier, D.A. (2003). Emergency department overcrowding and ambulance transport delays for patients with chest pain.CMAJ: Canadian Medical Association Journal 168(3):277-283.

Singer, A.J., Thode, H.C., Viccellio, P., \& Pines, J.M. (2011). The association between length of emergency department boarding and mortality. Academic Emergency Medicine 18: 13241329. Doi:10.1111/j.1553-2712.2011.01236.x

Soremekun, O.A., Shofer, F.S., Grasso, D., Mills, A.M., Moore, J., \& Datner, E.M. (2014). Thhe effect of an emergency department dedicated midtrack area on patient flow. Academic Emergency Medicine 21: 434-439. Doi: 10.1111/acem.12345

U.S. News \& World Report. (2013). Riverside methodist hospital: stats and services. Retrieved from: http://health.usnews.com/best-hospitals/area/oh/riverside-methodist-hospital-ohiohealth-6411110/details

Welch, S.J., Asplin, B.R., Stone-Griffith, S., Davidson, S.J., Augustine, J., \& Schuur, J. (2011). Emergency department operational metrics, measures and definitions: results of the second 
performance measures and benchmarking summit. Annals of Emergency Medicine (58)1: 3340. 